\title{
Intermidialidade: a arte como instrumento do discurso mercadológico
}

Anelise de Freitas; Faculdade de Letras, Universidade Federal de Juiz de Fora, Juiz de Fora, MG; E-mail: <anelisedefreitas@gmail.com>.

\section{Resumo}

A publicidade, em vários contextos, apropria-se da obra de arte para expor e gerar desejo sobre seus produtos. Dessa forma retira da arte, no caso a literatura, de sua zona de conforto canônica. $O$ trabalho observará algumas questões, como a banalização ou democratização da literatura dentro desse contexto discursivo; a linguagem da propaganda e necessário também será articular sobre a arte de consumo, que notoriamente é amparada pela indústria cultural e pelo capitalismo, que transformou a arte em algo frívolo, em mercadoria, acabando também por transformá-la em objeto de consumo. A intermidialidade será analisada através de estudos de caso, em que peças publicitárias e produtos de marketing utilizam-se da literatura.

Palavras-chave: publicidade, propaganda, arte de consumo, literatura, intermidialidade, Indústria Cultural

\section{Briefing}

O contexto social ao qual estamos entrelaçados atualmente mantém uma dificuldade de definições. Entretanto, objetiva-se trabalhar com dois discursos comunicativos: a publicidade e a literatura. Sabe-se da adversidade que essa proposição admite, por se tratar de dois objetos com certa intensidade e complexidade. A forma encontrada é traçar aspectos que possibilitem a análise de dois estudos de caso, para averiguar alguns aspectos da literatura, dos quais a propaganda se apropria para cumprir seu papel mercadológico.

O que seria a arte? E a publicidade? Qual o lugar da literatura dentro desses discursos? A publicidade, em vários contextos, apropria-se da obra de arte para expor e gerar desejo sobre seus produtos. A arte também institui outras formas de ver, fruir 
e... comprar (ou ser comprada). Vários autores brasileiros estiveram presentes na nossa propaganda e em seu desenvolvimento, contribuindo, então, para a estilística da redação publicitária, introduzindo grandes modificações nas mensagens de vendas.

\section{Discurso publicitário/Discurso literário}

O criativo de uma peça publicitária cumpre um objetivo: fazer uma peça a ser veiculada. Entretanto nenhum anúncio sai de uma agência sem antes passar pelo crivo do arte-finalista ou do cliente, estando perfeitamente adequada ao briefing. O artista, a seu modo, também delimita sua criatividade, a fim de ajustar detalhes da obra. Como então discernir sobre os dois discursos - publicitário e artístico? Não é raro ver publicitários que ocupam cadeiras artísticas (seja na área da escrita, da atuação ou artes plásticas). Há entre os discursos uma afinidade tênue, mas muito bem delimitada no momento de assumir a persona.

O artista busca provocar emoções ao proporcionar o prazer estético, comunicar aos outros seus pensamentos e também sentir prazer durante 0 ato criativo, explorando novas formas de expressão e documentação de seu tempo. Dessa forma a arte será uma simbiose entre forma e conteúdo.

No que toca ao conhecimento das verdades, o artista tem uma moralidade mais fraca do que o pensador; ele não quer absolutamente ser privado das brilhantes e significativas interpretações da vida, e se guarda contra métodos e resultados sóbrios e simples. Aparentemente luta pela superior dignidade e importância do ser humano; na verdade, não deseja abrir mão dos pressupostos mais eficazes para a sua arte, ou seja, o fantástico, mítico, incerto, extremo, o sentido para o simbólico, a superestimação da pessoa, a crença em algo miraculoso no gênio: considera o prosseguimento de seu modo de criar mais importante que a devoção científica à verdade em qualquer forma, por mais simples que ela se manifeste (Nietzsche 2005: 108).

Por outro lado, a publicidade explora aspectos do desejo humano, focando em atributos intangíveis de determinado produto. Segundo Carvalho (2007), "devemos considerar que, 
na realidade, a linguagem publicitária usa recursos estilísticos e argumentativos da linguagem cotidiana, ela própria voltada para informar e manipular". A palavra é muitas vezes o trunfo da publicidade, pois através dela expressa-se o que quiser. Ela tem o poder de enobrecer os produtos, de modifica-los e explora-los ao máximo. As palavras mostram ao consumidor o que lhe falta, mesmo que após a compra ele se sinta insatisfeito. Na publicidade os recursos fônicos, rimas e ritmo aspectos também verificados na poesia - são veementemente utilizados.

\section{Arte de Consumo}

O capitalismo, como o conhecemos hoje, iniciou sua evolução na passagem da Idade Média para a Moderna. A arte, até então tratada como algo frívolo, sem lucro, passa a ter valor com a chegada desse sistema, que transformou tudo em mercadoria. A arte foi transformada em objeto e o artista em produtor de mercadorias.

O patrocinador individual foi invalidado por um mercado livre no qual a avaliação das obras de arte se tornava difícil, precária, e onde tudo dependia de um conglomerado anônimo de consumidores chamado "público". A obra de arte foi sendo cada vez mais subordinada às leis da competição (Fischer, 2007: 59).

No capitalismo o homem vende a sua força de trabalho, fazendo um esforço alienante. Isso porque o trabalhador direciona sua atenção a fim de gerar lucro para seu empregador. A alienação nasce do momento em que o criador não possui mais noção sobre o objeto criado. $O$ artesão que produzia algo particularizado, tanto para si quanto para seu comprador, tinha contato com todas as partes da produção: desde a matéria-prima até o consumidor final. No mundo industrializado o produto e produtor não tem importância, servem apenas como formas de lucro.

A alienação tem uma influência decisiva sobre a arte e a literatura do século XX. Ela influenciou os grandes escritos de Kafka, a música de Schoenberg, os surrealistas, numerosos artistas, os "anti-romancistas", os "antidramaturgos", as sinistras farsas de Samuel 
Beckett e também a poesia dos beatniks americanos (Fischer 2007: 100).

Logo não Ihe resta tempo suficiente para a fruição, pois essa demanda certa paciência e dedicação. Esse homem não perde a capacidade de fruir, mas a mantém debilitada, tendo um contato anestésico com a arte, sendo por ele melhor aceito, então, justamente aquilo que é de mais fácil compreensão e que demande menos esforço para degustação. A arte cumpre também certo papel anti-alienante, no combate a mediocridade advinda do modo de produção capitalista. O poeta francês Charles Baudelaire incitou uma maneira de agir artisticamente denominada l'art pour l'art, ou seja, essa atitude ditava que a arte deveria ser feita apenas pelo prazer estético que despertava. Dessa forma estava firmado um protesto contra a vulgarização burguesa, que já àquela altura transformava tudo em mercadoria.

O escritor "livre", repelindo todos os laços, opondo-se ao mundo burguês e - inadvertidamente - reconhecendo o princípio burguês da produção para o mercado, apareceu pela primeira vez com o romantismo. Em seu protesto romântico contra os valores burgueses e em seu esforço de independência (que o levou até o papel de boêmio), tal escritor fez do seu trabalho precisamente aquilo que pretendia denunciar: uma mercadoria (Fischer, 2007: 67).

O próprio modernismo brasileiro, movimento talhado sobre 0 alicerce estético, psicológico e revolucionário, marcado pela intensa "Semana de 22", com artistas de expressão vanguardista, utilizou-se também de um sustentáculo comercial. Seus expoentes, buscando beber nas vanguardas europeias, necessitavam de uma grandiosa coxia monetária, afinal "só um grupo fixado na ponta (...) da burguesia culta" que "pudesse gozar de condições especiais como viagens à Europa (...) poderia renovar efetivamente o quadro literário do país" (Bosi, 2006). Não só literário, pressupõe-se.

Ninguém parece ter percebido que a Semana de 22, nossa primeira grande revolução cultural configurada, marcava como que a consciência histórica da luta que a partir de então iria caracterizar e convulsionar todos os aspectos da vida nacional: indústria vs. produção artesanal, cidade industrial vs. campo. Os poetas de 22 
viram isto claramente. Mas os historiadores e ideólogos, não. Por quê? Porque provinham das zonas rurais (Silva, 2007, apud Pignatari, 1998: 76).

Evidentemente, existe um modernismo de consumo. Pode-se ressaltar isso pelo fato de que o modernismo era elitista, mesmo que esse não fosse o cunho principal do movimento. Afinal, o "mecenato rural criou as condições favoráveis para a geração de 22 impor, como instância de legitimação, seus modelos estéticos estrangeiros" (Silva, 2007). Sabe-se também que outro aparato que evidencia o viés mercantil do modernismo brasileiro é o seu consumo não como movimento intelectual, mas sim como produto do sistema regido pelo capital.

Quando a rede de lojas $O$ Boticário lançou, em enorme outdoors, o famoso auto-retrato de Tarsila do Amaral, Manteau Rouge (1923), para promover uma nova linha de perfumes, uma coisa ficou clara: existe um Modernismo de consumo, alheio ou indiferente ao Modernismo acadêmico (Silva 2007: 161).

A Pop Art é a linha tênue entre os pessimistas e os eufóricos. Foi o marco do fim de valores adocicados - que passavam a se tornar ocos -, além de ser uma manifestação cultural alheia, que cresceu graças às condições capitalistas e das tecnologias industriais da sociedade vigente na época. Os estudiosos da psicologia, filosofia e sociologia, a pedido dos profissionais de marketing, analisaram o comportamento das massas, a fim de descobrir seus comportamentos de consumo, chegando à conclusão de que a massa era acomodada e podia consumir qualquer coisa que estivesse na moda. A Pop Art capturou, então, tudo que era consumido e estava em evidência naquele tempo e transformou em arte. Mais propriamente em arte de consumo.

\section{Estudo de Caso}

A utilização da literatura por meios publicitários outorga ao produto ou serviço certo status, entretanto seu uso demasiado gera confusão de conceitos e erroneamente tenta explicar algumas aglutinações, sem se basear na identidade que as 
une. Nesse meandro há três casos específicos sobre os quais poderíamos falar acerca da utilização de textos literários como artifícios de venda que: a "Avon", marca de cosméticos que utilizou trechos de poemas de Vinícius de Moraes como nomes de uma linha de perfumes, o jornal "Estado de São Paulo", que na época da ditadura militar brasileira inseria poemas de Camões no lugar das matérias censuradas e a Natura, que criou uma campanha publicitária baseada na poesia..

Há de se enfatizar um fator muito importante sobre a propaganda: ela não mente. A propaganda mostra outro viés do pensamento acerca daquele produto/serviço. Se o que está sendo oferecido contém muitos pontos negativos, o publicitário vai buscar, talvez o único, ponto positivo, através de um conceito criativo que procure enaltecer e vender através do emocional. Quando um produto utiliza a imagem de um artista para vender está buscando agregar valor ao produto/serviço através daquele que o vende, ou seja, essa pessoa contribuirá para a enfatização do conceito criativo. Com a arte dá-se o mesmo: os poemas utilizados contribuíram para o discurso da marca. Ao trazer conotações afetivas, a marca particulariza-se porque, segundo Carvalho (2007) "a marca torna-se um instrumento de categorização do real, um seletor - à sua maneira, ela categoriza o mundo".

$\mathrm{Na}$ propaganda, é empregada comumente uma figura de linguagem chamada metonímia, que é tomar a parte pelo todo, ou seja, dar o nome de uma marca para todo e qualquer produto similar àquele. Quando analisamos a marca "Avon", o jornal "Estado de São Paulo" ou a "Natura", podemos observar que, dessa perspectiva, os produtos obtém status de denominador, podendo a marca ser comparada aos poemas/poetas. Para vender o produto a marca precisa despertar ligações afetivas que garanta a fidelidade à marca: individualizando o produto, associando-o a imagens $e$ atribuindo-Ihe significações. Para Carvalho $(39,2007)$ conferir 
um nome próprio a um objeto permite uma "extraordinária promoção por meio da aquisição de identidade".

No caso das manifestações literárias na publicidade o ponto chave é que o redator publicitário não é um escritor literário, pois não devem ser líricos, nem podem ser obscuros, mas sim universalmente inteligíveis. É natural que a propaganda utilize outras linguagens dentro da sua própria, numa espécie de reprocessamento de outras linguagens. Desde o início da propaganda no Brasil, por exemplo, os poetas - homens habituados ao uso da palavra - escreviam os anúncios publicitários. Assim, como a literatura, a propaganda é alimentada pelas mensagens e promessas sedutoras. Afinal, é muitas vezes também através de signos linguísticos que a propaganda se expressa.

Por conseguinte é importante que o leitor - para ter sua própria conclusão - saiba que por detrás daquele texto existe um produtor, no caso o escritor/redator, afinal, "a reconstrução de uma intenção argumentativa é considerada como um prérequisito para o posicionamento crítico do leitor frente ao texto" (Kleiman, 2002).

É natural que a propaganda utilize outras linguagens dentro da sua própria, numa espécie de reprocessamento de outras elocuções. Desde o início da propaganda no Brasil, por exemplo, os poetas - homens habituados ao uso da palavra escreviam os anúncios publicitários. Assim, como a literatura, a propaganda é alimentada pelas mensagens e promessas sedutoras. Afinal, é muitas vezes também através de signos linguísticos que a propaganda se expressa. A "Avon", o jornal "Estadão" e a "Natura" estão ligados a conceitos muito bem delimitados pelo briefing, portanto é pautada pelos norteadores que levarão ao foco principal, a venda. Não somente, mas seria essa a linha de maior notoriedade (e tenuidade) que faria a distinção entre os dois discursos quando, por algum motivo, se veem entrelaçados ou em um mesmo contexto. Afinal, essas marcas estão assumindo novos discursos, se apropriando da 
literatura para cumprir seu foto. Portanto, é trabalho - também - do leitor de literatura e leitor de publicidade (sabendo que assumimos ambos os papeis) decodificar os valores estabelecidos pelas somas: publicidade mais literatura e literatura mais publicidade, sabendo que nessa equação a ordem dos fatores influi diretamente no seu resultado.

A "Avon" produziu uma linha, denominada "Mulher \& Poesia", ou seja, o público-alvo - mulheres - e o eixo criativo - poesia. Para tal, observa-se, criou, no total, seis fragrâncias, denominadas "Amor Total”, "Tua Graça”, "Luz dos Olhos Teus”, "Garota de Ipanema", "Samba da Rosa" e "Morena Flor". Todos os perfumes são títulos/trechos de canções ou poemas de Vinícius de Moraes, conhecido também pelos inúmeros casamentos e por enaltecer a figura feminina em seus versos. Quanto ao aspecto literário é um poeta de grande notoriedade, primando por um viés clássico - presença de sonetos, por exemplo - e com textos facilmente compreendidos e acessados. Observemos o "Soneto do Amor Total":

Amo-te tanto, meu amor... não cante O humano coração com mais verdade... Amo-te como amigo e como amante Numa sempre diversa realidade

Amo-te afim, de um calmo amor prestante $E$ te amo além, presente na saudade Amo-te, enfim, com grande liberdade Dentro da eternidade e a cada instante

Amo-te como um bicho, simplesmente De um amor sem mistério e sem virtude Com um desejo maciço e permanente

E de te amar assim, muito e amiúde É que um dia em teu corpo de repente Hei de morrer de amar mais do que pude

Os versos representam, estruturalmente, algo canônico: soneto, com estrutura ABAB ABBA CDC DCD, todos os versos decassílabos, ou seja, uma estrutura fixa e regular. O poema mostra inúmeras passagens de um eu-lírico, masculino, que esboça seu amor por uma mulher. Portanto, existe um diálogo com o público alvo. Algo similar acontece com os demais 
poemas, que são retirados da zona de conforto, em alguma forma, pois ausentam o poema do lugar canonizado da academia, sarau ou livros, por exemplo, levando-o para a inserção mercadológica. Como visto anteriormente a arte de consumo cumpriu um papel - seja pelo viés capitalista, seja pela crítica aguçada a esse sistema - de levar a arte para o mundo consumidor que, em suma, não é seu lugar de regra.

Em "Os Lusíadas", de Luiz de Camões, utilizado como suporte para matérias censuradas e em um videoteipe para um comercial institucional do jornal "Estado de São Paulo", há uma reiteração da identidade lusitana. Na obra, primeira epopeia em língua portuguesa, como em inúmeros outros autores posteriormente, existe um entrosamento da história literária com a própria busca daquele povo pela essência verdadeira do ser português. O desbravador Vasco da Gama é aquele capaz de conhecer novos mundos, de dar ao país novas terras e, principalmente, fazer daquele povo um povo destemido e notório. Logo, ao utilizar trechos desse poema no lugar das matérias censuradas pela ditadura ou ser recitado pelos jornalistas em uma propaganda, cria um endereçamento: o jornal, assim como Vasco da Gama, é também destemido, empenhado com a verdade e, obviamente, está imbuído de sentimentos nobres. Nos primeiros versos do "Canto I", observamos:

As armas e os Barões assinalados

Que da Ocidental praia Lusitana

Por mares nunca de antes navegados

Passaram ainda além da Taprobana,

Em perigos e guerras esforçados

Mais do que prometia a força humana,

E entre gente remota edificaram

Novo Reino, que tanto sublimaram

Camões emprega uma sinédoque - figura de estilo, referente à metonímia, ou seja, pela qual se manifesta o todo pela parte reciprocamente - em "Ocidental praia Lusitana"; Vasco da Gama, desbravador, passa por mares nunca dantes navegados e "além da Taprobana", que atualmente é o Sri Lanka; se 
superando, pois a força humana bem menos prometia, passando por guerras e perigos, enfim, edifica o "Novo Reino, que tanto sublimaram". Novamente, o poema não toma para si apenas significações canônicas, do que seria um poema, mas sim conotações que abrangem a significância do jornal.

E no último caso, a marca "Natura", que utilizou em sua campanha não somente o verso, mas poetas. Para a linha de produtos "Natura Tododia" o conceito foi pensado com base no mote criativo "Mais poesia para sua rotina". As poetas brasileiras - em profunda ascensão e notoriedade - Ana Guadalupe, Bruna Beber, Lilian Aquino, Elisa Buzzo e Marina Wisnik - foram convidadas para falarem sobre o que é a poesia e como é possível encontra-la no cotidiano, ou seja, como é possível ver poesia todo dia. Além de um vídeo disponibilizado na internet as poetas foram incumbidas de encontrar poesia no jornal (um veículo diário e tradicional, que dialoga com o conceito e a linha de produtos). Elas eliminavam palavras das matérias contidas no jornal e extraiam poemas com as palavras restantes. $\mathrm{O}$ aspecto intermidiático se encontra não no fato de dispor poetas em um comercial falando sobre essa arte, mas sim em contrata-las para criar poemas - extraídos de jornais para uma campanha publicitária. Além de vender a ideia de que é possível encontrar poesia no dia-a-dia a marca também coloca mulheres aparentemente comuns fazendo esse trabalho. O público foi convidado para fazer esse exercício e compartilhar nas redes sociais, o que gera interação e share.

\section{Considerações Finais}

Ao observarmos esses exemplos podemos crer que o processo intermidiático está presente a partir do momento em que observamos uma relação entre as mídias discursivas, com objetivos distintos. Não há o surgimento de uma terceira mídia, mas os elementos da literatura passam a fazer parte da propaganda.

A escrita, por outro lado, é uma mídia separada e particular. Ela pode ficar transparente na leitura de um 
texto impresso convencionalmente: para muitos leitores a fonte e o tamanho das letras normalmente não influenciam na recepção e interpretação do texto verbal (mas podem influenciar no prazer da leitura). Mas, além de existir em muitas formas de representação da linguagem verbal - alfabética, ideogramática, hieroglífica, cuneiforme, etc. - escrita, manual ou impressa, consiste de signos sui generis, com um grande leque de expressividade (Clüver 2011: 13).

A publicidade trabalha com valores estabelecidos e, utiliza nesse sentido, a arte como um recurso de venda. Quando um publicitário define uma criação ele não a faz sozinho, pois só chega a uma criação publicitária depois de analisar detalhadamente um documento chamado briefing. Esse documento determina o planejamento estratégico e criativo de uma campanha ou, simplesmente, de uma peça. Nele, como o próprio nome atesta, contem um resumo do que deve ser abordado. Um artista, por mais mambembe ou pouco influente, cria também com delimitações criativas. Mas essas delimitações são intrínsecas e movidas somente por seus desejos. Se durante um poema o poeta deseja colocar uma palavra que mude o sentido de todo o texto ele não será repreendido e ainda assim estará cumprindo seu papel de poeta. O publicitário não utiliza uma palavra que mude todo o significado de um texto porque ele cria com delimitações expostas em um briefing. Então como explicar o caso da Capela Sistina, encomendada a Michelangelo pela igreja? Nada impede que um artista execute um trabalho sob encomenda, mas nem tudo que um artista executa pode ou deve ser considerada arte.

As técnicas de reprodução aplicadas à obra de arte modificam a atitude da massa com relação à arte. Muito retrógrada face a um Picasso, essa massa torna-se bastante progressista diante de um Chaplin, por exemplo. O caráter de um comportamento progressista cinge-se a que 0 prazer do espectador e a correspondente experiência vivida ligam-se, de maneira direta e íntima, à atitude do aficionado. (...) O fato de que, a partir do século XIX, tiveram a permissão de serem mostrados a um público considerável corresponde a um primeiro sintoma dessa crise não apenas desfechada para invenção da fotografia, mas, de modo relativamente independente de tal descoberta, pela intenção da obra de arte de se endereçar às massas (Benjamim 1955: s/p) 
Embora a publicidade e a arte bebam uma no trabalho da outra, elas não são a mesma coisa. Entretanto, claramente, há muito que as uma, como o fato de que ambas necessitam de criadores capazes de construir um desejo entre o público. Muitos cânones são estabelecidos através do aparato literário, mas o discurso publicitário desmistifica esse embasamento canônico (assim como canoniza outros discursos). Vários autores brasileiros estiveram presentes na nossa propaganda e em seu desenvolvimento. Contribuindo, então, para a estilística da redação publicitária, introduzindo grandes modificações nas mensagens de vendas.

A arte é necessária assim como a poesia ou a filosofia: para combater a alienação proveniente do modo de produção capitalista. E só depois do sistema capitalista a arte, situada acima da mediocridade, pode ter relevância como arte de protesto.

O ponto chave para esse entrosamento é que texto publicitário não é literatura - sendo discursos distintos - já que "os redatores de anúncios não podem ser líricos, obscuros ou exotéricos, e sim universalmente inteligíveis" (Huxley, 1941). É natural que a propaganda utilize outras linguagens dentro da sua própria, numa espécie de reprocessamento de outras linguagens. Dessa forma, é preciso que também o público saiba discernir sobre o local do qual o discurso é emanado: a publicidade na literatura versus a literatura na publicidade.

\section{Referências}

Benjamin, W. (2013). A obra de arte na era da sua reprodutibilidade técnica. Retrieved from: http://www.deboraludwig.com.br/arquivos/benjamin_reprodutibilidade_ tecnica.pdf.

Bosi, A. (2006). História Concisa da Literatura Brasileira. São Paulo: Cultrix.

Camões, L. (2013). Os Lusíadas. Retrieved from : http://www.citi.pt/ciberforma/ana_paulos/ficheiros/lusiadas.pdf. 
Candido, A. (1997). Formação da literatura brasileira: momentos decisivos. 8. ed. Belo Horizonte, Itatiaia.

Carvalho, N. (2007). Publicidade: a linguagem da sedução. São Paulo, Editora Ática.

Clüver, C. (2011). Intermidialidade. In: Pós.. Belo Horizonte, v.1, n.2, p. 8-23, Nov. 2011.

Coutinho, A. (1960). Conceito de literatura brasileira. Rio de Janeiro: Livraria Acadêmica..

Duarte, R. (2010). Indústria Cultural: uma introdução. Rio de janeiro, Editora FGV.

Fischer, E. (2002). A Necessidade da Arte. 9ª Edição. Rio de Janeiro, Guanabara Koogan.

Huxley, A. (1941). A difícil arte de redigir anúncios. Revista do Globo, 301, 06.

Kleiman, A. B. (2002). Texto e Leitor: aspectos cognitivos da leitura. São Paulo: Pontes.

Marthe, M. (2010). Imagem é Tudo. Veja. São Paulo: Abril, Edição 2.156, ano 43, no11.

Moraes, V. (2009). Antologia Poética. São Paulo: Companhia de Bolso.

Nietzche, F. W. (2005). Humano, demasiado humano: um livro para espíritos livres. São Paulo: Companhia das Letras.

Silva, A. P. (2009). Mario e Oswald: uma história privada do Modernismo. Rio de Janeiro: 7 Letras.

Tufano, D. (1983). Estudos de Literatura Brasileira. 3aㅗ Edição. São Paulo: Moderna.

Waiteman, F. (2006). Manual prático de criação publicitária: o dia-adia da criação em uma agência. São Paulo: Nobel. 